\title{
A New Speed Control Technique for a Separately Excited Direct Current Motor by PID Controller
}

\author{
O.Akar, U.K.Terzi and O.Ozgonenel
}

\begin{abstract}
In this study, by deriving electro-mechanic mathematical model of separately excited direct current motor (SEDCM) via equivalent circuit, a new control block diagram has been formed. By using this block diagram, state space model of SEDCM has been created and block diagram of motor has been formed in Matlab Simulink environment. Steady state and transient values of armature current, emf, produced torque, speed and position angle have been obtained using this new model. By adding PID controller to block diagram, SEDCM has been remodeled. Finally, results of steady state and transient analysis of SEDCM have examined through speed control of the proposed model.
\end{abstract}

It is reported that the suggested modeling technique is able to analyze the speed control of the SEDCM.

Index Terms-PID controller, separately excited direct current motor (SEDCM), speed control, equivalent circuit.

\section{INTRODUCTION}

$\mathrm{T}$ HIS DOCUMENT is in parallel to rapid development of technology, from toy production to industry even from robots to space devices, many products contain motors powered by electrical energy. One of them is Direct Current motor. In comparison to alternating current motor, speed control of direct current motor is easier [1,2]. Therefore, as it used to be, today they still take their place in industrial applications. Day by day, by the development of technology, their use in new products increases. High power DC motors are generally used in paper factories, weaving machines, ship propellers, printing machines and elevators and, low power DC motors are frequently used with motor controllers for the parts which especially require speed and position control in robotics, 3D printers, copying machines, moving parts of computers, radar tracking systems $[3,4]$.

O. AKAR, is with Department of Mechatronic Program, Gedik Vocational High School Istanbul Gedik University, 34700, Istanbul, Turkey, (e-mail: onur.akar@gedik.edu.tr)

U.K.TERZI, is with Department of Electrical-Electronics Engineering, Marmara University, Istanbul, Turkey, (e-mail: terzi@ marmara.edu.tr) (1)

O. OZGONENEL, is with Department of Electrical-Electronics Engineering, Ondokuz Mayis University, Samsun, Turkey, (e-mail: okanoz@omu.edu.tr) iD

Manuscript received September 13, 2017; accepted January 08, 2018. DOI: $10.17694 /$ bajece.410209
There are many types of DC motors which can be classified according to their winding and connection types and purpose of usage. The constant increase in the number of direct current motors and their dependence on the technology has made the development of the control of these motors important. In parallel to developing technology, the variety of DC motors and continuous increase of their usage area have made the development of the control of these motors important.

\section{DIRECT CURRENT MOTORS AND PID CONTROLLER}

The Electrical motors can be classified as alternating current motors and direct current motors. Direct current motors among themselves also can be classified in two groups according to their excitation type and connection type. According to excitation type, there are separately excited and self-excited direct current motors and, according to connection type there are shunt, serial and compound direct current motors. Except these, there are step and servo motors driven with DC [5].

\section{A. Separately Excited DC Motors}

Armature and excitation windings of SEDCM are independent from each other. They need to be excited by two different DC source. These are called separately excited DC motors [5]. As known, DC motors consist of two electrical parts which are armature and excitation circuit and one mechanical part which transmits torque. As known, DC motors consist of two electrical parts which are armature and excitation circuit and one mechanical part which transmits torque. While DC machine works as generator, torque is applied to DC machine, but while DC machine works as motor, torque is applied to load which is coupled to shaft. A dc machine which works as motor is represented with general equivalent electromechanic system given in Fig. 1 [3].

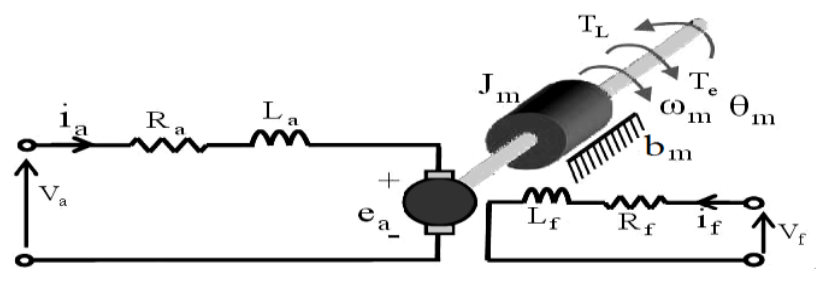

Fig.1. Equivalent electromechanic scheme of separately excited DC motors [3,6-8]. 
Where;

$\mathrm{R}_{\mathrm{a}}$ : Armature resistance;

$\mathrm{L}_{\mathrm{a}}:$ Armature inductance;

$\mathrm{i}_{\mathrm{a}}:$ Armature current;

$\mathrm{V}_{\mathrm{a}}$ : Input voltage;

$\mathrm{e}_{\mathrm{a}}$ : Back electromotive force (EMF);

$\mathrm{R}_{\mathrm{f}}$ : Field resistance;

$\mathrm{L}_{\mathrm{f}}$ : Field inductance;

$\mathrm{i}_{\mathrm{f}}$ : Field current;

$\mathrm{V}_{\mathrm{f}}$ : Field voltage;

$\mathrm{T}_{\mathrm{e}}$ : Motor torque;

$\theta_{m}$ : Position angle;

$\omega_{m}:$ An angular velocity of rotor;

$\mathrm{J}_{\mathrm{m}}$ : Rotational inertia of motor bearing;

$\mathrm{b}_{\mathrm{m}}$ : Friction constant;

K: EMF-Torque constant.

These types of motor are not preferred in industry because they are separately excited. Even if they are used, excitation windings are connected in parallel with armature and it is used as shunt DC motor. Apart from this, they are used for experimental purposes in the organizations provided with technical training.

\section{B. Proportional- integral and derivative (PID) controller}

PID controller is built up by using three controllers as seen in Fig. 2. In system, by using proportional, integral and derivative controls, control signal is generated. The system works with $K_{P}, K_{I}$ and $K_{D}$ constants. A low pass filter is used to reduce noise of derivative control [8-10]

$$
\mathrm{K}_{D} S \approx \frac{\mathrm{K}_{D} S}{1+S \tau}
$$
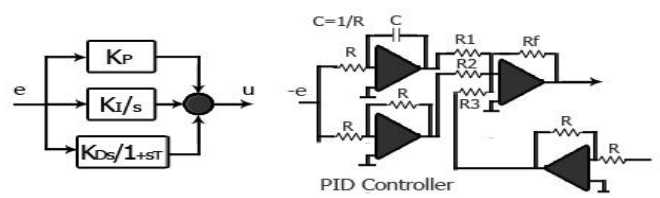

Fig.2. Block and circuit diagram of PID controller [6-11]

\section{STATE SPACE MODEL}

IDEs of armature circuit of SEDMC are given in Eq. 2 and Eq. 3. IDEs of excitation circuit of SEDMC are given in Eq. 4 and Eq. 5, and IDEs of mechanical system of SEDMC are given from Eq. 6 through Eq. 9.

$$
\begin{gathered}
V_{a}(t)=L_{a} \cdot \frac{d i_{a}(t)}{d t}+R_{a} \cdot i_{a}(t)+e_{a}(t) \\
L_{a} \cdot \frac{d i_{a}(t)}{d t}=V_{a}(t)-R_{a} \cdot i_{a}(t)-e_{a}(t) \\
V_{f}(t)=L_{f} \cdot \frac{d i_{f}(t)}{d t}+R_{f} \cdot i_{f}(t) \\
L_{f} \cdot \frac{d i_{f}(t)}{d t}=V_{f}(t)-R_{f} \cdot i_{f}(t)
\end{gathered}
$$

$$
\begin{gathered}
\frac{d \theta_{m}(t)^{2}}{d t^{2}}=\frac{d \omega_{m}(t)}{d t} \\
\frac{d \theta_{m}(t)}{d t}=\omega_{m}(t) \\
T_{e}(t)=J_{m} \cdot \frac{d \omega_{m}(t)}{d t}+b_{m} \cdot \omega_{m}(t)+T_{L}(t) \\
J_{m} \cdot \frac{d \omega(t)}{d t}=T_{e}(t)-b_{m} \cdot \omega_{m}(t)-T_{L}(t)
\end{gathered}
$$

The electromechanical interaction of the SEDCM is given in equations Eq.10- Eq.23 [6-8,10-18].

$$
\begin{gathered}
B=k_{f} \cdot i_{f} \\
k_{m}=2 \cdot N \cdot l \cdot r \\
K=k_{m} \cdot k_{f} \\
T_{e}=N \cdot l \cdot r \cdot i_{a} \cdot B \\
T_{e}=k_{m} \cdot i_{a} \cdot k_{f} \cdot i_{f} \\
T_{e}=k_{m} \cdot k_{f} \cdot i_{a} \cdot i_{f} \\
T_{e}=K \cdot i_{a} \cdot i_{f} \\
e_{a}=2 \cdot N \cdot l \cdot r \cdot \omega_{m} \cdot B \\
e_{a}=k_{m} \cdot \omega_{m} \cdot k_{f} \cdot i_{f} \\
e_{a}=k_{m} \cdot k_{f} \cdot \omega_{m} \cdot i_{f} \\
e_{a}=K \cdot \omega_{m} \cdot i_{f} \\
L_{a} \cdot \frac{d i_{a}(t)}{d t}=V_{a}(t)-R_{a} \cdot i_{a}(t)-K \cdot \omega_{m}(t) \cdot i_{f}(t) \\
L_{f} \cdot \frac{d i_{f}(t)}{d t}=V_{f}(t)-R_{f} \cdot i_{f}(t) \\
J_{m} \cdot \frac{d \omega_{m}(t)}{d t}=K \cdot i_{a}(t) \cdot i_{f}(t)-b_{m} \cdot \omega_{m}(t)-T_{L}(t)
\end{gathered}
$$

Block diagram which is shown in Fig.3 is formed by using IDEs given in Eq. 21,22,23. [6-8,10-18].

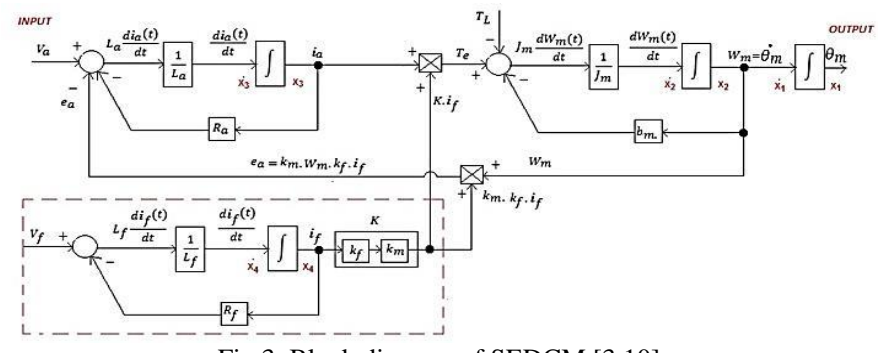

Fig.3. Block diagram of SEDCM $[3,10]$

On the basis of simulation block diagram shown in Fig. 3, state space equation formulated in Eq.24-30 of SEDCM is obtained by assigning $\mathrm{X}_{1}, \dot{\mathrm{X}}_{1}, \mathrm{X}_{2}, \dot{\mathrm{X}}_{2}$ variables. 


$$
\begin{aligned}
& \dot{X}_{1}=X_{2} \\
& \dot{X}_{2}=\frac{1}{J_{m}} \cdot\left[-b_{m} \cdot X_{2}+k_{f} \cdot N \cdot l \cdot r \cdot X_{3} \cdot X_{4}+k_{f} \cdot N \cdot l \cdot r \cdot X_{4} \cdot X_{3}-T_{L}\right] \\
& \dot{X}_{3}=\frac{1}{L_{a}} \cdot\left[-R_{a} \cdot X_{3}-k_{f} \cdot N \cdot l \cdot r \cdot X_{2} \cdot X_{4}-k_{f} \cdot N \cdot l \cdot r \cdot X_{4} \cdot X_{2}+V_{a}\right] \\
& \dot{X}_{4}=\frac{1}{L_{f}} \cdot\left[-R_{f} \cdot X_{4}+V_{f}\right] \\
& {\left[\begin{array}{l}
\dot{X}_{1} \\
\dot{X}_{2} \\
\dot{X}_{3} \\
\dot{X}_{4}
\end{array}\right]=\left[\begin{array}{cccc}
0 & 1 & 0 & 0 \\
0 & -\frac{b_{m}}{J_{m}} & \frac{k_{f} \cdot N \cdot l \cdot r}{J_{m}} \cdot X_{4} & \frac{k_{f} \cdot N \cdot \cdot \cdot r}{J_{m}} \cdot X_{3} \\
0 & -\frac{k_{f} \cdot N \cdot l_{a}}{L_{a}} \cdot X_{4} & -\frac{R_{a}}{L_{a}} & -\frac{k_{f} \cdot N \cdot l r}{L_{a}} \cdot X_{2} \\
0 & 0 & 0 & \frac{-R_{f}}{L_{f}}
\end{array}\right] \cdot\left[\begin{array}{l}
X_{1} \\
X_{2} \\
X_{3} \\
X_{4}
\end{array}\right]+\left[\begin{array}{ccc}
0 & 0 & 0 \\
-\frac{1}{J_{m}} & 0 & 0 \\
0 & \frac{1}{L_{a}} & 0 \\
0 & 0 & \frac{1}{L_{f}}
\end{array}\right] \cdot\left[\begin{array}{l}
T_{L} \\
V_{a} \\
V_{f}
\end{array}\right]} \\
& {[y]=\left[\begin{array}{llll}
1 & 0 & 0 & 0
\end{array}\right] \cdot\left[\begin{array}{l}
X_{1} \\
X_{2} \\
X_{3} \\
X_{4}
\end{array}\right]}
\end{aligned}
$$

By using Eq. 24 through Eq. 29, Eq.30 is obtained [10,19].

$$
y=X_{1}
$$

\section{MATLAB SIMULINK ENVIRONMENT AND SIMULATION OF CONTROL SYSTEM}

\section{A. Simulation model in Matlab Simulink Environment for SEDCM}

Motor parameters of SEDCM are given in Table 1. Bu using these values, Matlab/Simulink model of system which is shown in Fig.4 is formed. Display modules are inserted to the certain points to monitor the results of steady state and transient analysis.

TABLE II MOTOR PARAMETERS OF SEDCM
\begin{tabular}{|c|c|c|}
\hline \multicolumn{3}{|c|}{ DC Motor Parameters } \\
\hline Parameter & Value & Unit \\
\hline $\mathrm{R}_{\mathrm{a}}$ & 0.26 & Ohm \\
\hline $\mathrm{R}_{\mathrm{f}}$ & 260 & Ohm \\
\hline $\mathrm{L}_{\mathrm{a}}$ & 0.025 & Henry \\
\hline $\mathrm{L}_{\mathrm{f}}$ & 0.28 & Henry \\
\hline $\mathrm{V}_{\mathrm{a}}$ & 420 & Volt \\
\hline $\mathrm{k}_{\mathrm{f}}$ & 0.08135 & $\mathrm{~V} \cdot \mathrm{s} / \mathrm{rad}$ \\
\hline $\mathrm{B}_{\mathrm{m}}$ & 0.028 & $\mathrm{Nm} \cdot \mathrm{s} / \mathrm{rad}$ \\
\hline $\mathrm{J}_{\mathrm{m}}$ & 0.5 & $\mathrm{~kg}-\mathrm{m}^{2}$ \\
\hline $\mathrm{T}_{\mathrm{L}}$ & 8 & $\mathrm{Nm}$ \\
\hline
\end{tabular}

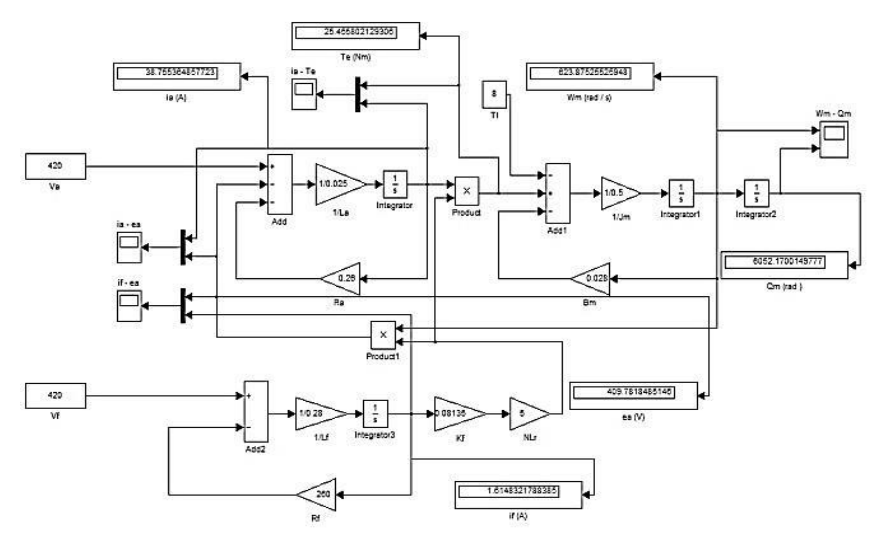

Fig.4. Matlab/Simulink simulation model of SEDCM
The graphs of some values such as armature current, emf, armature current, produced torque, excitation current and position angle vs time are given below before PID controller is added to system in Matlab/Simulink environment for SEDCM.

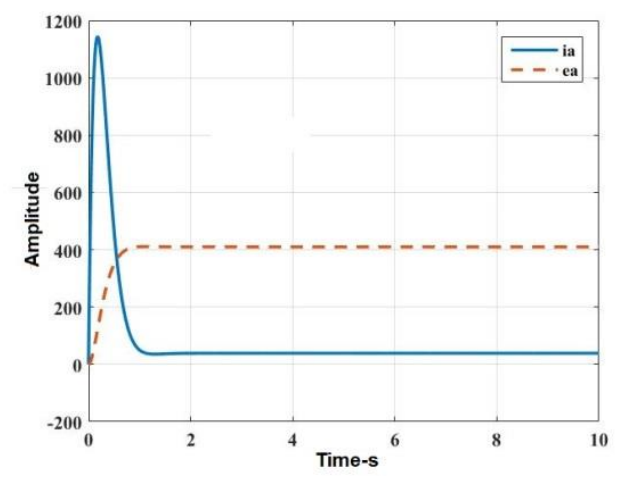

Fig.5. Graphs of armature current and emf vs time of SEDCM

When Fig. 5 is examined, it is figured out that armature current increases logarithmically approximately up to $1150 \mathrm{~A}$ in a few hundred milliseconds and after 1 second, it gets stable and takes value of $38.755 \mathrm{~A}$. Emf reaches $409.781 \mathrm{~V}$ in a few hundred milliseconds and gets stable.

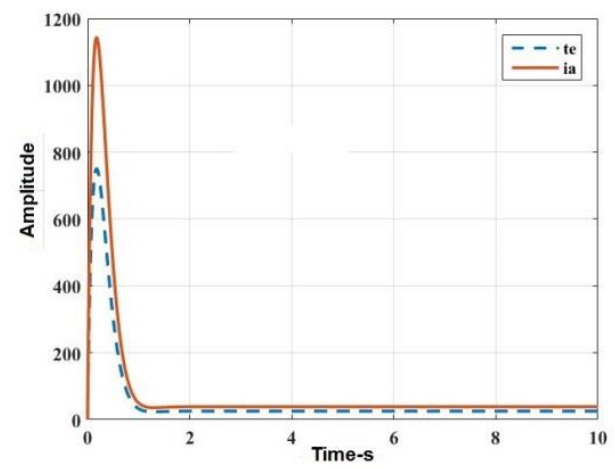

Fig.6. Graphs of armature current and produced torque vs time of SEDCM

When Fig. 6 is examined it is figured out that armature current increases up to $1150 \mathrm{~A}$ in a few hundred milliseconds and after 1 second, it gets stable and takes value of $38.755 \mathrm{~A}$. Produced torque simultaneously with armature current increases up to $700 \mathrm{Nm}$ in a few hundred milliseconds and after 1 second, it gets stable and takes value of $24.455 \mathrm{Nm}$.

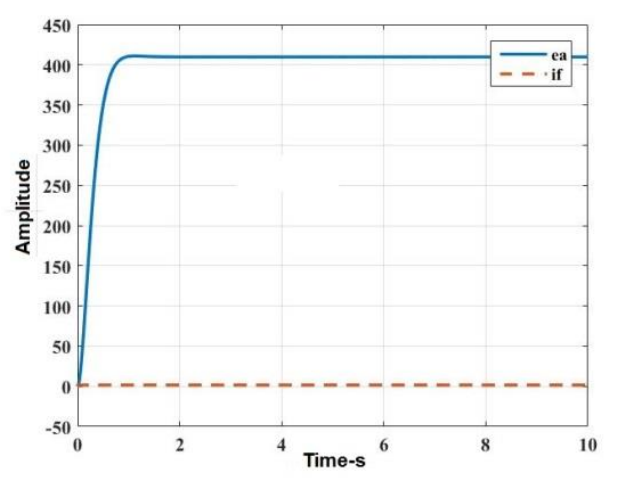

Fig.7. Graphs of excitation current and emf vs time of SEDCM 
When Fig. 7 is examined, it is figured out that with excitation current of $1.614 \mathrm{~A}$ emf reaches $409.781 \mathrm{~V}$ in a few hundred milliseconds and then gets stable.

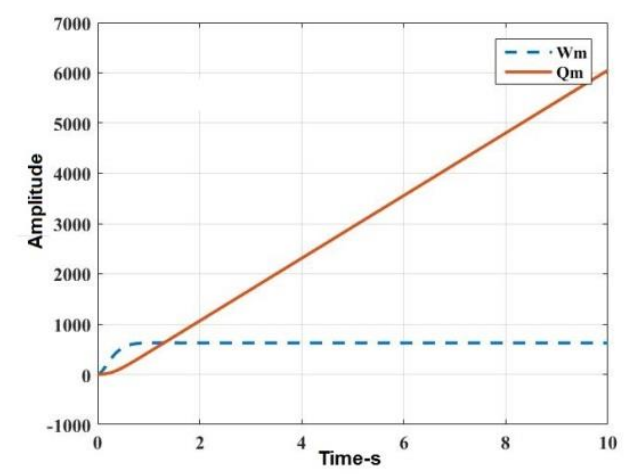

Fig.8. Graphs of speed and position angle vs time of SEDCM

When Fig. 8 is examined, it is figured out that speed of motor reaches approximately $600 \mathrm{rad} / \mathrm{s}$ in a few hundred milliseconds and after 1 second, it gets stable and takes value of $623.87 \mathrm{rad} / \mathrm{s}$. Position angle increases logarithmically in a few hundred milliseconds and after that it keeps increasing linearly and get value of $6052.17 \mathrm{rad}$ at 10th second.

The speed value of motor is measured as $623.87 \mathrm{rad} / \mathrm{s}$ which is equal to $5957.33 \mathrm{rpm}$ and this value is used as a reference value for control models.

\section{B. Simulation model in Matlab Simulink Environment with PID controller for SEDCM}

The model of control system with PID controller in the Matlab/Simulink environment can be seen in Fig. 9. Since the speed of motor is normally $623.87 \mathrm{rad} / \mathrm{s}$, reference value is fixed to this value. After that, by varying resistance and capacity values in related layers of control circuit control parameters $\mathrm{K}_{\mathrm{P}}, \mathrm{K}_{\mathrm{I}}, \mathrm{K}_{\mathrm{D}}$ and $\mathrm{K}_{\mathrm{P} 1}, \mathrm{~K}_{\mathrm{I} 1}$ and $\mathrm{K}_{\mathrm{D} 1}$ are adjusted and it is ensured that the output speed is $653,87 \mathrm{rad} / \mathrm{s}$.

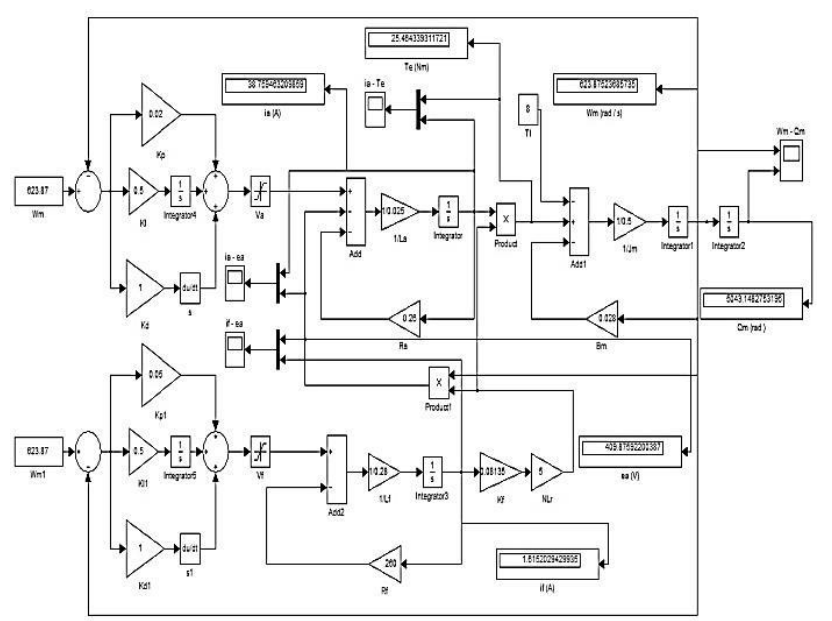

Fig.9. Matlab/Simulink simulation model with PID controller of SEDCM.

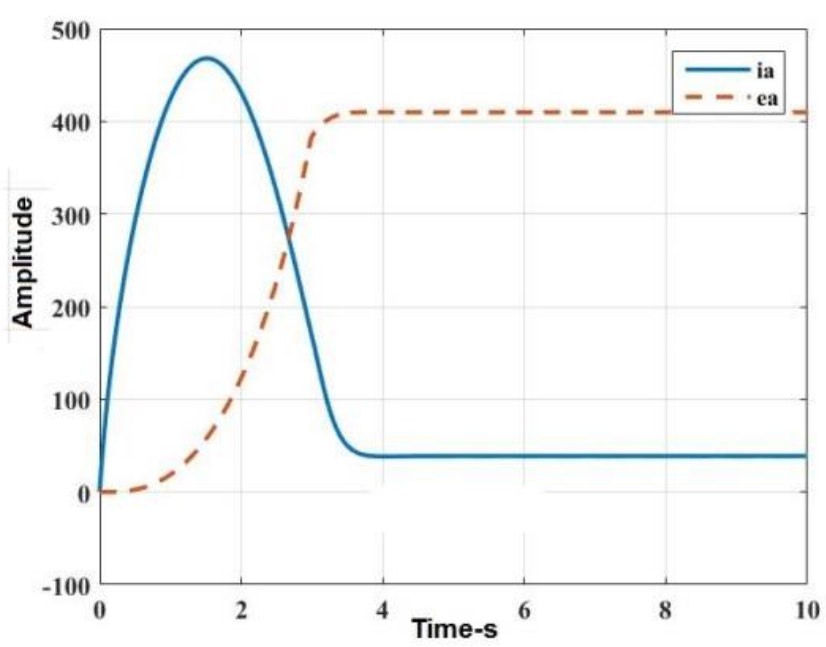

Fig.10. Graphs of armature current and emf vs time of SEDCM with PID controller

When Fig. 10 is examined, it is figured out that armature current increases logarithmically approximately up to $500 \mathrm{~A}$ in a few seconds and decreases logarithmically approximately up to $38.755 \mathrm{~A}$. Later on, it gets stable. Emf reaches $409.781 \mathrm{~V}$ in a few seconds and gets stable.

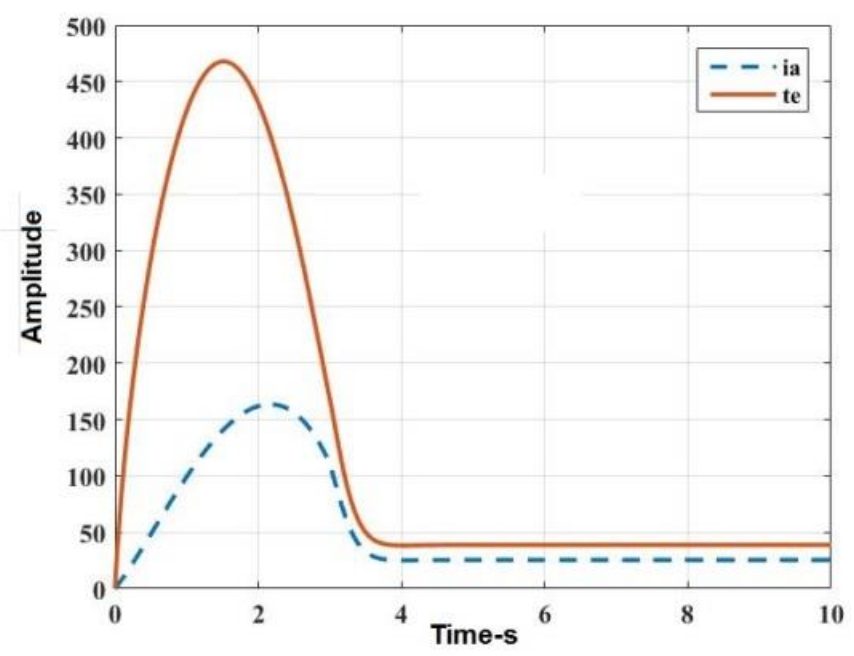

Fig.11. Graphs of armature current and produced torque vs time of SEDCM with PID controller

When Fig. 11 is examined, it is figured out that armature current increases logarithmically approximately up to $500 \mathrm{~A}$ in a few seconds and decreases logarithmically approximately up to 38.759 A. Later on, it gets stable. Produced torque logarithmically increases up to $150 \mathrm{Nm}$ in a 2.2 seconds and decreases logarithmically up to $25.464 \mathrm{Nm}$ in $3.5 \mathrm{~s}$. Later on, it gets stable with value of $25.464 \mathrm{Nm}$. 


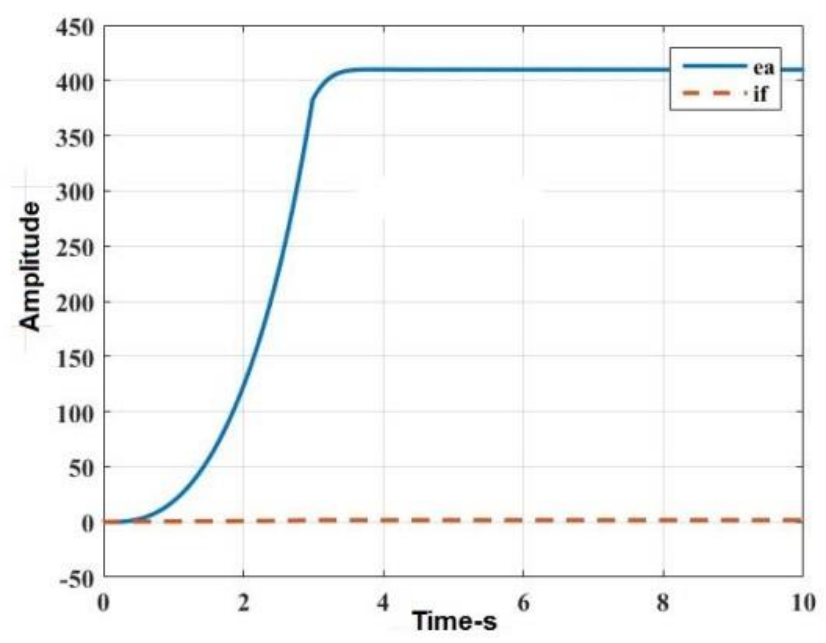

Fig.12. Graphs of excitation current and emf vs time of SEDCM with PID controller

When Fig. 12 is examined, it is figured out that with excitation current of $1.615 \mathrm{~A}$, emf increases logarithmically and reaches $409.781 \mathrm{~V}$ in 3 seconds. Later on, then gets stable.

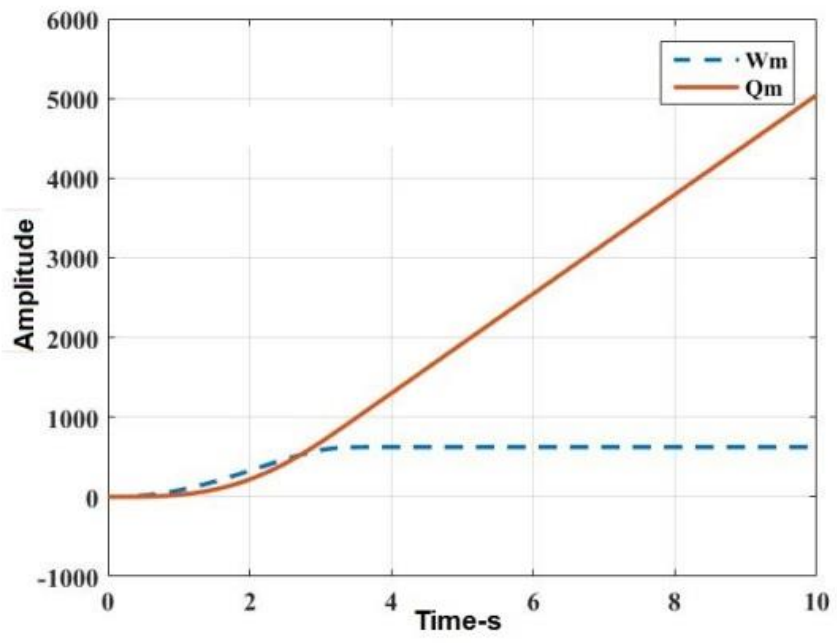

Fig.13. Graphs of speed and position angle vs time of SEDCM with PID controller

When Fig. 13 is examined, it is figured out that speed of motor reaches approximately $623.87 \mathrm{rad} / \mathrm{s}$ in 3 seconds, it gets stable and takes value of $623.87 \mathrm{rad} / \mathrm{s}$. Position angle increases logarithmically in 3 seconds and after that it keeps increasing linearly and get value of 5043.14 rad at 10th second.

The speed value of motor is measured as $623.87 \mathrm{rad} / \mathrm{s}$ which is equal to $5957.33 \mathrm{rpm}$ and this value is used as a reference value for control models.

\section{CONCLUSION}

Measured steady state values of SEDCM are almost same with and/or without proposed new speed control technique except for position angle. But, the results for transient values are not the same and show difference as seen in related graphs. The harmonization, peak and stability values and durations provided by proposed new speed control technique differ. It is figured out that SEDCM with proposed speed control technique has lower startup current in shorter duration and reaches stable sooner.

\section{REFERENCES}

[1] ALLAOUA, B.; GASBAOUI, B.; MEBARKI, B.: "Setting Up PID DC Motor Speed Control Alteration Parameters Using Particle Swarm Optimization Strategy", Leonardo Electronic Journal of Practices and Technologies ISSN 1583-1078, Issue 14, January-June 2009, p. 19-32

[2] BANSAL, U., K.; NARVEY, R.: "Speed Control of DC Motor Using Fuzzy PID Controller, Advance in Electronic and Electric Engineering, ISSN 2231-1297, Volume 3, Number 9 (2013), pp. 1209-1220

[3] ALTAŞ, İ.,H,: "Endüvi ve Uyarma Birleşik Kontrollü DA Motorlarının Modellenmesinde Sebep-Sonuç Yaklaşımı", Otomasyon Dergisi, Bileşim yayınları, Mart 2008, Sayfalar: 102-110.

[4] GEORGE, M.: "Speed Control of Separately Excited DC Motor", American Journal of Applied Sciences 5 (3): 227-233, 2008 ISSN 1546-9239

[5] ÖZDEMIR, A.; "Elektrik Motorları ve Sürücüleri”, Birsen yayınevi, ISBN: 978-975-511-489-7, 2007, İstanbul.

[6] SINGHAL, R.; PADHEE, S.; KAUR, G.: "Design of Fractional Order PID Controllerfor Speed Control of DC Motor", International Journal of Scientific and Research Publications, Volume 2, Issue 6, June 20121 ISSN 2250-3153

[7] HUANG, G.; LEE, S.: "PC-based PID Speed Control in DC Motor", 978-1-4244-1724-7/08/\$25.00 C2008 IEEE, ICALIP2008

[8] ALI, F., H.; HUSSEIN, M., M.; ISMAEL;S.; M.; B.: "LabVIEW FPGA Implementation Of a PID Controller For D.C. Motor Speed Control", 20101 st International Conferance on Energy, Power and Control (EPC-IQ), Collage of Engineering, University of Basrah, Basrah, Iraq, November 30-December 2. 2010

[9] http://www.yildiz.edu.tr/ omurlu/CF/OKI/12.pdf , 07.05.2017

[10] ALTAŞ, İ.,H,: "Otomatik Kontrol Sistemleri Ders Notları", KTÜ, Mühendislik Fakültesi, Elektrik-elektronik Mühensdisliği, 2009, Trabzon.

[11] KANOJIYA, R., G.; MEShraM, P., M.: "Optimal Tuning of PI Controller for Speed Control of DC motor drive using Particle Swarm Optimization", 978-1-4673-2043-6/12/\$31.00 C2012 IEEE

[12] TANG, J.: "Pid Controller Using The Tms320c31 Dsk With On-Line Parameter Adjustment For Real-Time Dc Motor Speed And Position Control”, 0-7803 -7090-2/01/ \$10.00 @ 2001IEEE, ISIE 2001, Pusan, KOREA

[13] YU, G., R.; HWANG, R.,C.:" Optimal PID Speed Control of Brushless DC Motors Using LQR Approach", 2004 IEEE International Conference on Systems, Man and Cybernetics, 0-7803-85667/04/\$20.00 (C) 2004 IEEE.

[14] SHIN, H., B.; PARK, J., G.: "Anti-Windup PID Controller With Integral State Predictor for Variable-Speed Motor Drives", IEEE Transactions On Industrial Electronıcs, Vol. 59, No. 3, March 2012

[15] DUMAN, S.; MADEN, D.; GÜVENÇ, U.: "Determination of the PID Controller Parameters for Speed and Position Control of DC Motor using Gravitational Search Algorithm", ", 7th International Conference on Electrical and Electronics Engineering (ELECO 2011), 1-4 December, Bursa, TURKEY, pp. 226-230, 2011.

[16] THOMAS, N.; POONGODİ, P.: "Position Control of DC Motor Using Genetic Algorithm Based PID Controller", Proceedings of the World Congress on Engineering 2009 Vol II WCE 2009, July 1 - 3, 2009, London, U.K.

[17] MEShrAM, P., M.; KANOJIYA, R., G.: "Tuning of PID Controller using Ziegler-Nichols Method for Speed Control of DC Motor", IEEEInternational Conference On Advances In Engineering, Science And Management (ICAESM -2012) March 30, 31,2012 117

[18] NASRI, M.; NEZAMABADI, H.; MAGHFOORI, M.: "A PSO-Based Optimum Design of PID Controller for a Linear Brushless DC Motor", Proceedings Of World Academy Of Science, Engıneerıng And Technology Volume 20 April 2007 Issn 1307-6884

[19] SALEH, A.; AL-MASHAKBEH, O.: "Proportional Integral and Derivative Control of Brushless DC Motor", European Journal of Scientific Research ISSN 1450-216X Vol.35 No.2 (2009), pp.198-203

[20] Matlab/SimulinkTM, The Mathworks, Inc, http://www.mathworks.com/ (10 Mayıs 2017 tarihinde aktif olan link 


\section{BIOGRAPHIES}

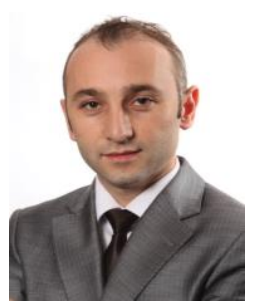

Onur AKAR was born in Giresun in 1981. He received his B.S. degree from Electrical Education Department of Technical Education Faculty of University of Marmara, Istanbul, in 2005 and his M.Sc. degree from Electrical Education Department of Institute of Pure and Applied Sciences, University of Marmara, İstanbul, in 2011. He also received B.S degree from Electrical and Electronics Engineering Department of Engineering Faculty of Karadeniz Technical University, Trabzon, in 2017. He has been currently attending doctorate programme in Electrical and Electronics Engineering department of Institute of Pure and Applied Sciences of Marmara University, Istanbul.

He has been working as a Lecturer at Mechatronics Program of Vocational High School of Istanbul Gedik University since 2010. He served as the Head of Electrical Department of Vocational High School of Gedik University in Istanbul between 2012 and 2015. He is the author of 2 article and one book chapter. His research interests include Control Systems, Renewable Energy Systems and Power Systems.

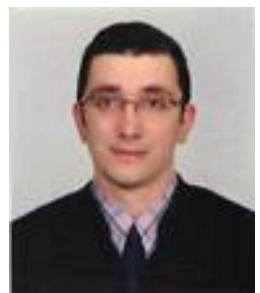

Umit K. TERZI was born in Zonguldak in 1968. He received his B.S. degree from Electrical Education Department of Technical Education Faculty of University of Marmara, Istanbul, in 1989 and his M.Sc. and Ph.D. degree from Electrical Education Department of Institute of Pure and Applied Sciences, University of Marmara, Istanbul, in 1994 and 2000 respectively.

From 1989 to 1996, he worked as a research assistant, from 1996 to 2000 as a lecturer, from 2000 to 2013 as an Assistant Prof. Dr. for university of Marmara. Since 2013 he has been working as an Associate Prof. Dr. for Electrical and Electronics department of Technology Faculty of Marmara University and Electrical Education Department of Technical Education Faculty where he is head of department.

His research interests include Electrical Machinery, Power Systems, Energy Transmission and Distribution, Renewable Energy Systems.

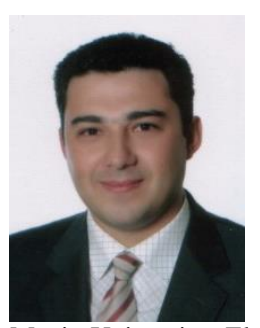

Okan OZGONENEL was born in Samsun in 1967. He received his B.S and MSc. degrees from Marmara University in 1989 and 1991, respectively. He received his $\mathrm{PhD}$ degree from Sakarya University in 2001.

From 1989 to 1991, he worked for Goztepe SSK Hospital as an engineer. Then he received a special grant and promoted as Lecturer in Amasya Technical and Vocational Higher School by means of World Bank Second Industrial Training Project. He has worked there for 10 years and then joined Ondokuz Mayis University, Electrical \& Electronic Engineering Department in 2002. $\mathrm{He}$ was promoted as full Professor in 2014 and since then he has been working for Ondokuz Mayis University where he is head of department.

His main researches include power system modeling and protection and renewables, too. applications. 